RUNNING HEAD: CLIMATE ATTENTION AND PERCEPTION

Accepted at Current Opinion in Behavioral Sciences

\title{
Attentional and perceptual biases of climate change
}

\author{
Yu Luo ${ }^{1}$ and Jiaying Zhao ${ }^{1,2}$ \\ ${ }^{1}$ Department of Psychology, ${ }^{2}$ Institute for Resources, Environment and Sustainability \\ University of British Columbia
}

Please address correspondence to:

Jiaying Zhao Department of Psychology

Institute for Resources, Environment and Sustainability University of British Columbia Vancouver, B.C., Canada, V6T 1Z4 Email: jiayingz@psych.ubc.ca 


\begin{abstract}
Climate change is the most significant global challenge facing humanity. Despite the unequivocal scientific evidence and the overwhelming adverse impacts of climate change, there is a growing divide in the beliefs on the anthropogenic causes of climate change. To explore the underlying cognitive mechanisms of this divide, we review recent studies revealing a number of attentional and perceptual biases that can give rise to the divergent opinions on climate change. With these cognitive insights in mind, we discuss several communication approaches (e.g., framing, visualization) that have the potential to mitigate the attentional and perceptual biases, with the broader goal of minimizing polarizing views and promoting actions to address climate change.
\end{abstract}




\section{Introduction}

Climate change has emerged as a significant global issue with unequivocal scientific evidence showing anthropogenic causes. In fact, scientific consensus on climate change has been reached by $90-100 \%$ of actively publishing climate scientists according to six independent studies [1]. Despite the overwhelming scientific evidence, some people still remain skeptical about anthropogenic climate change and refuse to take actions to mitigate the adverse impacts. For example in the United States, public opinion tends to polarize along political parties, where $89 \%$ of the Democrats see global warming as mainly due to human activities, but only $35 \%$ the Republicans do [2]. This gap has not only persisted but grown over time, along with a widening divide in climate policy priorities and support [3]. For example, states where people pay more attention to climate change and perceive climate change as a threat are more likely to adopt climate policies [4].

What explains the growing divide between different groups? In this paper, we review recent studies revealing a number of attentional and perceptual biases that can give rise to the polarizing views on climate change and subsequent actions. This is also an opportunity to demonstrate how cognitive science can offer unique theoretical perspectives, methods, and evidence to complement insights from social psychology, in the service of addressing global challenges. At the end of the paper, we discuss several communication approaches that target some of the attentional and perceptual biases to minimize the divide and promote actions to mitigate climate change. Table 1 shows a summary of attentional and perceptual biases and the corresponding communication tools to mitigate these biases. 
Table 1. Attentional and perceptual biases and the corresponding communication tools

\begin{tabular}{lll}
\hline Type of bias & Examples & Communication tools \\
\hline Attentional & $\begin{array}{l}\text { People with different political orientations } \\
\text { attend to different aspects of global } \\
\text { temperature information [5] }\end{array}$ & $\begin{array}{l}\text { Align climate } \\
\text { communication with } \\
\text { people's ideologies and } \\
\text { motivations to capture } \\
\text { their attention }\end{array}$ \\
& $\begin{array}{l}\text { People concerned with climate change attend } \\
\text { more readily to climate-related words or } \\
\text { images [8, 9] }\end{array}$ & \\
& $\begin{array}{l}\text { Attended environmental risks are judged to } \\
\text { be more severe than unattended risks [11] }\end{array}$ & \\
& $\begin{array}{l}\text { Predispositions (e.g., knowledge, personal } \\
\text { experience) increase climate risk perception }\end{array}$ & $\begin{array}{l}\text { Frame climate change } \\
\text { consistently with people's } \\
\text { values }\end{array}$ \\
& $\begin{array}{l}\text { Perception of both in-group and out-group } \\
\text { Perceptual }\end{array}$ & $\begin{array}{l}\text { Provide accurate } \\
\text { information on in-group } \\
\text { and out-group norms }\end{array}$ \\
& $\begin{array}{l}\text { 16, 17, 18] } \\
\text { Perception of greenhouse gas emissions } \\
\text { associated with individual actions or objects } \\
\text { is often incorrect [21, 22, 23, 24] }\end{array}$ & $\begin{array}{l}\text { Simplify complex } \\
\text { information through } \\
\text { visualization }\end{array}$ \\
& & \\
\hline & & \\
& & \\
& & \\
& &
\end{tabular}

\section{Attentional biases to climate information}

A growing body of evidence suggests that people tend to pay attention to information consistent with their pre-existing beliefs, motivations, and values [e.g., 6,7]. In the context of climate information, the motivated attention framework has been proposed to describe the attentional biases that are driven by prior motivations and can shape climate perception and actions [5]. In a series of eye-tracking experiments by Luo and Zhao (2019), participants who were more liberal tended to pay more visual attention to the rising phase of the global temperature curve (after 1990) relative to the flatter phase (from 1940 to 1980). To seek causal evidence for the role of attention in climate actions, the authors manipulated attention by 
highlighting the rising phase (i.e., stronger climate change evidence) in red in one condition, and highlighting the flatter phase (i.e., weaker climate change evidence) in red in another condition. By deliberately drawing their attention to the rising phase the global temperature curve, liberals were more likely to sign climate petitions and to donate to environmental causes than when attention was drawn to the flatter phase. However, this effect was absent for conservative participants. This framework suggests that people with different political orientations have different attentional biases to climate change information, and these biases can alter their subsequent climate actions [5].

In addition to global temperature information, another study using an attentional blink paradigm showed that liberals high in climate concerns were more accurate at identifying climate-related words (e.g., carbon) than neutral words (e.g., coffee) in a rapid serial visual presentation; in contrast, conservatives low in climate concerns were no better at seeing climaterelated words over neutral words, suggesting that people with different political orientations show distinct attentional priorities to climate change [8]. Another study used a dot-probe task [9], where a climate-relevant image and a neutral image were presented on the left and the right side of the screen, followed by a target dot presented briefly on one side of the screen, and participants had to respond to the location of the dot as fast as they could. The response time difference between the two image locations was used to measure the attentional bias to climate change. For example, faster responses to the dot presented on the same side as the climaterelevant image than the neutral image would indicate an attentional bias toward climate image. The findings showed that people with greater pro-environmental attitudes were faster to respond to climate change-relevant images (e.g., melting ice) than to neutral images (e.g., buildings), suggesting a greater attentional bias to climate change stimuli for these individuals [9]. In a 
follow-up experiment, positively valenced images of climate change solutions (e.g., windmills) captured attention more strongly than negatively valenced images of causes (e.g., pollution) and effects of climate change (e.g., flood) [10].

Greater attention to climate change is not only a product of prior attitudes and orientations, but also a cause for greater concerns for climate change. In a series of spatial cueing experiments by Mrkva and colleagues (2020), participants viewed images of environmental risks (e.g., hurricane) and their attention was drawn to a subset of these risks either through bottom-up salience or top-down guidance. It was found that participants subsequently rated attended risks as more severe, more frightening, and of higher priority than unattended risks, suggesting that attention can increase risk perception [11].

These studies together provide evidence for a central tenet in the motivated attention framework [5], where prior beliefs and motivations shape visual attention to climate change, and increased or decreased attention to climate change in turn reinforce prior beliefs and motivations, thus creating a positive feedback loop, leading to more polarized views. This framework is based on previous work on motivated reasoning. For example, the identity-protective cognition thesis suggests that people with high numeracy skills use their quantitative reasoning capacity to selectively interpret quantitative information on controversial issues like climate change to comply with their prior political values [6,7]. Likewise, people with high science literacy and education tend to show greater polarization on controversial topics, because they are more proficient in interpreting evidence in the direction conforming to their identity [12]. Attention could be a mediator of motivated reasoning: people with higher numeracy skills and science literacy are more capable of selectively attending to information consistent with their motivations 
during the reasoning process, and the resulting interpretation can further reinforce their preexisting motivations.

\section{Perceptual biases of climate change}

Attentional biases can often give rise to subsequent perceptual biases. For example, in the eye-tracking experiments mentioned earlier, more dwell time on the rising phase of the global temperature curve relative to the flatter phase was positively correlated with higher estimates of global temperature [5]. Greater visual attention to images of environmental risks can heighten the perception of risks [11]. A conceptual model proposed that the perception of climate risks is determined by a number of factors, including knowledge about the causes, impacts, and responses to climate change [13], personal experience with extreme weather events, and social norms [14]. Under the motivated attention framework, it is conceivable that greater knowledge about climate change can bias attention to climate-related information, which can generate more knowledge and higher perceived climate risks. Personal experience with extreme weather events can increase the salience of climate-related information, in similar ways as people with posttraumatic stress disorder tend to perceive greater threats of certain stimuli that trigger the stress response. In other words, the relationship between climate risk perception and factors such as knowledge and personal experience can be moderated by attentional and perceptual processes.

Regarding social norms, the perception of out-group norms can be biased. One account suggests that people often exaggerate the degree of opposition from out-group members, forming a false sense of polarization on climate change $[15,16]$. The misperceived out-group norms can be a psychological barrier to bipartisan climate policy making in the U.S.. In addition, the perception of in-group norms can be biased as well. In one study, people are less willing to share their true opinions on climate change if they believe other in-group members hold different 
views on climate change [17]. This may suppress different voices to be heard within the group, thus distorting the perception of in-group norms. This said, speaking up can sometimes backfire. For example, conservative individuals remain skeptical about climate change even when the message is conveyed by a religious authority who aligns with conservatives' values. In one study, conservative individuals perceived Pope Francis to be less credible after becoming aware of the encyclical stating that climate change is a serious issue [18].

Beyond attention, a number of biases have been found to shape the perception of climate change information, contributing to greater polarization. People who regard the economic system as justified (i.e., system justification bias) are motivated to falsely recall climate evidence to be less serious, which is associated with higher skepticism in the existence of climate change [19]. Another bias is that people selectively expose themselves to news media that is consistent with their dispositional motivations, which can further reinforce their pre-existing beliefs about climate change [20].

In addition to selective perception, many people are skeptical about human-caused climate change because they do not understand the mechanism of greenhouse gas (GHG) emissions. One study showed that people have virtually no knowledge of the chemical or physical mechanism of global warming, particularly the carbon dioxide accumulation problem, which could lead to the denial of the existence of global warming [21]. However, when an explanation of the mechanism was provided, people are more likely to believe in climate change $[22]$.

Another perceptual bias is the underestimation of carbon footprints associated with actions or objects. One study found that people tend to underestimate the GHG emissions associated with individual actions and they are incapable of translating the climate impacts 
across different actions [23]. Another study demonstrated the negative footprint illusion, which is the tendency to estimate a lower carbon footprint of a combined group of environmentally friendly items and ordinary conventional items, than the carbon footprint of conventional items alone, even though the combined group contains more items [24]. These findings suggest that the perception of GHG emissions is often incorrect and there is a large gap between what they think they know and what is the reality.

\section{Designing climate communication tools}

So far we have reviewed a number of attentional and perceptual biases that can contribute to the divergent opinions on climate change. With these cognitive insights in mind, we will discuss several communication approaches (e.g., framing, visualization) that have the potential to mitigate the attentional and perceptual biases, with the broader goal of minimizing polarization and promoting actions to address climate change.

Since people with different political orientations show different attentional biases to global temperature information, climate communication needs to align with the ideological beliefs and motivations to capture people's attention. For liberals or people who are concerned about climate change, one method is to draw their attention to salient climate change information, such as rising global temperature and climate solutions, to encourage them to take climate actions. However, for conservative individuals or people who are skeptical about climate change, drawing their attention to the rising global temperature may backfire [5]. An alternative approach could be to draw their attention to aspects of climate change which are more consistent with their ideologies (e.g., national security, public health).

Another approach is to frame climate change consistently with their values, such as framing actions that mitigate climate change as benefiting collective economic development or 
building a more moral and caring community [25], or framing pro-environmental options as benefits for future generations [26]. While these are gain frames, loss frames can also be used to highlight the potential losses from a collective failure to address climate change [27]. To avoid negative reactions, carbon offsets can be framed as an upstream remedy for service provider's actions (e.g., flight fuel production) rather than a downstream tax imposed to consumers' behavior (e.g., airplane travel) [28]. Other positive frames include promoting national security, Christian stewardship, and public health, but they were largely ineffective in changing climate beliefs; however, one negative frame on climate change denial significantly reduced conservatives' belief in climate change and their support for climate policy [29]. Since the perception of in-group and out-group norms is often biased, one approach is to provide accurate information on social norms for both in-groups and out-groups [16], and also ensure that the source of evidence is credible to the specific group [30].

To mitigate the gap between perception and reality, one method to inform people about GHG emissions of actions and items is to use simple, accessible, and interactive visualizations [31]. For example, showing the extent of GHG emissions of the life cycle of food with light-bulb minutes can effectively deter consumers from purchasing food with higher emissions [32]. When presenting future global temperature information, providing individual model estimates in addition to the statistical range can be an effective tool to influence policymakers [33]. Thus, simplifying complex climate change information and providing more transparent information can correct the misperceived reality of climate change.

Another communication tool is to create an open-minded state to encourage the acceptance of climate change, such as offering a self-affirmation task before exposing people to climate information [34], encouraging discussions on global warming with friends and family to 
learn influential facts [35], sharing information from the opposite partisanship [36], or providing additional information that explains the scientific consensus information $[37,38]$. In designing specific communication methods, we should target specific cognitive processes associated with the audience group to effectively persuade people, for example, correcting distortions in their memory with repeated engagement or implementing retrieval cues [39].

Communicating climate evidence to the public and correcting misperception of climate change are only the first steps. The ultimate goal is to promote personal actions to mitigate climate change. Several studies have shown that climate change risk perception does not fully reflect a behavioral willingness $[40,41]$ and people with low cognitive resources have difficulties to project their pro-environmental attitudes to daily pro-environmental behavior [42]. Thus, future studies need to focus on translating attitude to actions to mitigate climate change. In the last decade, interventions based on behavioral insights have gained a lot of traction as tools to address climate change. For example, providing the increasing prevalence of vegetarian diets increased meatless meal orders [43]. However, a recent meta-analysis of randomized controlled trials showed that many interventions to change household behaviors had a small effect on actual climate change mitigation actions and failed to sustain behavior change over time [44]. Given this finding, effective and lasting behavioral interventions remain to be discovered.

\section{Conclusions}

The current review provides an exploration of the attentional and perceptual biases that can contribute to the divergent opinions on climate change. As the need to address anthropogenic climate change becomes increasingly urgent, it is imperative to promote effective solutions to change human behavior using cognitive insights. This is also an opportunity to demonstrate the value of cognitive science in addition to social psychology in solving global challenges. As an 
initial effort, we have provided a number of communication approaches that have the potential to reduce polarization and promote climate actions. 


\section{Acknowledgments}

This work was supported by the Canada Research Chairs program (to JZ) and Social Sciences and Humanities Research Council Doctoral Fellowship (to YL). 


\section{References}

1. Cook J, Oreskes N, Doran PT, Anderegg WRL, Verheggen B, Maibach EW, Carlton JS, Lewandowsky S, Skuce AG, Green SA, et al.: Consensus on consensus: A synthesis of consensus estimates on human-caused global warming. Environ Res Lett 2016, 11.

2. Brenan M, Saad L: Global Warming Concern Steady Despite Some Partisan Shifts. Gallup 2018,

3. Pew Reaearch Center: The Partisan Divide on Political Values Grows Even Wider. 2017 ,

4. Bromley-Trujillo R, Poe J: The importance of salience: Public opinion and state policy action on climate change. J Public Policy 2020, 40:280-304.

5. Luo Y, Zhao J: Motivated attention in climate change perception and action. Front Psychol 2019, 10.

6. Kahan DM, Peters E, Dawson EC, Slovic P: Motivated numeracy and enlightened selfgovernment. Behav Public Policy 2017, 1:54-86.

7. Nurse MS, Grant WJ: I'll See It When I Believe It: Motivated Numeracy in Perceptions of Climate Change Risk*. Environ Commun 2020, 14:184-201.

8. Whitman JC, Zhao J, Roberts KH, Todd RM: Political orientation and climate concern shape visual attention to climate change. Clim Change 2018, 147:383-394.

9. Carlson JM, Lehman BR, Thompson JL: Climate change images produce an attentional bias associated with pro-environmental disposition. Cogn Process 2019, 20:385-390.

10. Carlson JM, Kaull H, Steinhauer M, Zigarac A, Cammarata J: Paying attention to climate change: Positive images of climate change solutions capture attention. $J$ Environ Psychol 2020, 71:101477. 
11. Mrkva K, Cole JC, Van Boven L: Attention Increases Environmental Risk Perception. J Exp Psychol Gen 2020, 150:83-102.

12. Drummond C, Fischhoff B: Individuals with greater science literacy and education have more polarized beliefs on controversial science topics.pdf. Proc Natl Acad Sci U $S$ A 2017, 114:9587-9592.

13. Shi J, Visschers VHM, Siegrist M, Arvai J: Knowledge as a driver of public perceptions about climate change reassessed. Nat Clim Chang 2016, 6:759-762.

14. van der Linden S: The social-psychological determinants of climate change risk perceptions: Towards a comprehensive model. J Environ Psychol 2015, 41:112-124.

15. Ehret PJ, Van Boven L, Sherman DK: Partisan Barriers to Bipartisanship: Understanding Climate Policy Polarization. Soc Psychol Personal Sci 2018, 9:308-318.

16. Van Boven L, Ehret PJ, Sherman DK: Psychological Barriers to Bipartisan Public Support for Climate Policy. Perspect Psychol Sci 2018, 13:492-507.

17. Geiger N, Swim JK: Climate of silence: Pluralistic ignorance as a barrier to climate change discussion. $J$ Environ Psychol 2016, 47:79-90.

18. Landrum AR, Lull RB, Akin H, Hasell A, Jamieson KH: Processing the papal encyclical through perceptual filters: Pope Francis, identity-protective cognition, and climate change concern. Cognition 2017, 166:1-12.

19. Hennes EP, Ruisch BC, Feygina I, Monteiro CA, Jost JT: Motivated Recall in the Service of the Economic System: The Case of Anthropogenic Climate Change. $J$ Exp Psychol Gen 2016, 145:755-771.

20. Bolin JL, Hamilton LC: The News You Choose: news media preferences amplify views on climate change. Env Polit 2018, 27:455-476. 
21. Newell BR, Kary A, Moore C, Gonzalez C: Managing the Budget: Stock-Flow Reasoning and the CO2 Accumulation Problem. Top Cogn Sci 2016, 8:138-159.

22. Ranney MA, Clark D: Climate Change Conceptual Change: Scientific Information Can Transform Attitudes. Top Cogn Sci 2016, 8:49-75.

23. Wynes S, Zhao J, Donner SD: How well do people understand the climate impact of individual actions? Clim Change 2020, 162:1521-1534.

24. Holmgren M, Andersson H, Sörqvist P: Averaging bias in environmental impact estimates: Evidence from the negative footprint illusion. J Environ Psychol 2018, 55:48-52.

25. Bain PG, Milfont TL, Kashima Y, Bilewicz M, Doron G, Garoarsdóttir RB, Gouveia V V., Guan Y, Johansson LO, Pasquali C, et al.: Co-benefits of addressing climate change can motivate action around the world. Nat Clim Chang 2016, 6:154-157.

26. Weber EU: Breaking cognitive barriers to a sustainable future. Nat Hum Behav 2017, 1.

27. Bain PG, Bongiorno R: It's not too late to do the right thing: Moral motivations for climate change action. Wiley Interdiscip Rev Clim Chang 2020, 11:1-8.

28. Hardisty DJ, Beall AT, Lubowski R, Petsonk A, Romero-Canyas R: A carbon price by another name may seem sweeter: Consumers prefer upstream offsets to downstream taxes. J Environ Psychol 2019, 66:101342.

29. McCright AM, Charters M, Dentzman K, Dietz T: Examining the Effectiveness of Climate Change Frames in the Face of a Climate Change Denial Counter-Frame. Top Cogn Sci 2016, 8:76-97.

30. Druckman JN, McGrath MC: The evidence for motivated reasoning in climate change 
preference formation. Nat Clim Chang 2019, 9:111-119.

31. Harold J, Lorenzoni I, Shipley TF, Coventry KR: Cognitive and psychological science insights to improve climate change data visualization. Nat Clim Chang 2016, 6:1080 1089.

32. Camilleri AR, Larrick RP, Hossain S, Patino-Echeverri D: Consumers underestimate the emissions associated with food but are aided by labels. Nat Clim Chang 2019, 9:53-58

33. Bosetti V, Weber E, Berger L, Budescu D V., Liu N, Tavoni M: COP21 climate negotiators' responses to climate model forecasts. Nat Clim Chang 2017, 7:185-189.

34. Wong-Parodi G, Feygina I: Understanding and countering the motivated roots of climate change denial. Curr Opin Environ Sustain 2020, 42:60-64.

35. Goldberg MH, van der Linden S, Leiserowitz A, Maibach E: Perceived Social Consensus Can Reduce Ideological Biases on Climate Change. Environ Behav 2020, 52:495-517.

36. Guilbeault D, Becker J, Centola D: Social learning and partisan bias in the interpretation of climate trends. Proc Natl Acad Sci U S A 2018, 115:9714-9719.

37. van der Linden S, Leiserowitz A, Rosenthal S, Maibach E: Inoculating the Public against Misinformation about Climate Change. Glob Challenges 2017, 1:1600008.

38. Cook J, Lewandowsky S: Rational Irrationality: Modeling Climate Change Belief Polarization Using Bayesian Networks. Top Cogn Sci 2016, 8:160-179.

39. Van Bavel JJ, Pereira A: The Partisan Brain: An Identity-Based Model of Political Belief. Trends Cogn Sci 2018, 22:213-224.

40. Xie B, Brewer MB, Hayes BK, McDonald RI, Newell BR: Predicting climate change risk perception and willingness to act. J Environ Psychol 2019, 65:101331. 
41. Hornsey MJ, Harris EA, Bain PG, Fielding KS: Meta-analyses of the determinants and outcomes of belief in climate change. Nat Clim Chang 2016, 6:622-626.

42. Langenbach BP, Berger S, Baumgartner T, Knoch D: Cognitive Resources Moderate the Relationship Between Pro-Environmental Attitudes and Green Behavior. Environ Behav 2020, 52:979-995.

43. White K, White K, Hardisty DJ: How to SHIFT Consumer Behaviors to be More Sustainable: A Literature Review and Guiding Framework. J Mark 2019, 83:22-49.

44. Nisa CF, Belanger JJ, Schumpe BM, Faller DG: Meta-analysis of randomised controlled trials testing behavioural interventions to promote household action on climate change. Nat Commun 2019, 10. 


\section{Annotated References}

* of special interest

** of outstanding interest

*7. Luo Y, Zhao J: Motivated attention in climate change perception and action. Front Psychol 2019, 10.

The authors propose an motivated attention framework that suggests an attentional divide between liberals and conservatives in the perception of climate evidence and in climate actions.

*8. Whitman JC, Zhao J, Roberts KH, Todd RM: Political orientation and climate concern shape visual attention to climate change. Clim Change 2018, 147:383-394.

The study shows that liberals high in climate concerns prioritized their attention towards climate-related information over neutral infromation but conversatives low in climate concerns did not.

*11. Mrkva K, Cole JC, Van Boven L: Attention Increases Environmental Risk Perception. J Exp Psychol Gen 2020, 150:83-102.

The study demonstrates that participants perceived attended risks to be more severe, more frightening, higher priority, and more distinctive than unattended risks.

*24. Holmgren M, Andersson H, Sörqvist P: Averaging bias in environmental impact estimates: Evidence from the negative footprint illusion. J Environ Psychol 2018, 55:48-52.

This study demonstrates the negative footprint illusion, which is the tendency to estimate a lower carbon footprint of a combined group of environmentally friendly items and ordinary conventional items, than the carbon footprint of conventional items alone. 
*44. Nisa CF, Belanger JJ, Schumpe BM, Faller DG: Meta-analysis of randomised controlled trials testing behavioural interventions to promote household action on climate change. Nat Commun 2019, 10.

The meta-analysis shows that some behavioral interventions (e.g., social comparison messages) have little effect on climate change mitigation and failed to sustain behavior change over time. 